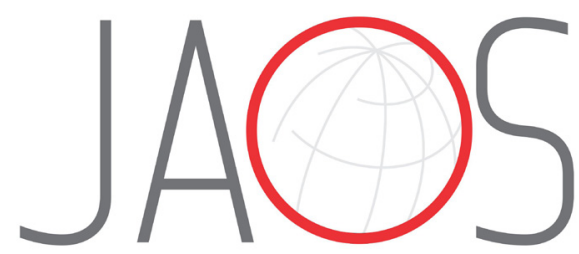

JOURNAL OF APPLIED ORAL SCIENCE

\title{
Porosity, water sorption and solubility of denture base acrylic resins polymerized conventionally or in microwave
}

\section{Abstract}

Rosana Marques Silva FIGUERÔA ${ }^{1}$ Bruna CONTERNO ${ }^{1}$ César Augusto Galvão ARRAIS 1 Carolina Yoshi Campos SUGIO² Vanessa Migliorini URBAN ${ }^{1}$ Karin Hermana NEPPELENBROEK ${ }^{2}$
Submitted: August 8, 2017 Modification: September 15, 2017 Accepted: September 16, 2017

Corresponding address: Vanessa Migliorini Urban Departamento de Odontologia Universidade Estadual de Ponta Grossa. Av. General Carlos Cavalcanti 4748 - Uvaranas 84030-900 - Ponta Grossa - PR - Brasil. Phone: 55-42-32203104 - Fax: 55-42-32203102 e-mail: vanurban@yahoo.com
The proper selection of polymerization cycle is important to prevent overheating of the monomer that could cause degradation, porosity and, consequently, deleterious effects on the denture base properties. Objective: This study evaluated the porosity, water sorption and solubility of acrylic resins (Vipi Cril-VC and Vipi Wave-VW) after conventional or microwave polymerization cycles. Material and Methods: Specimens $(n=10)$ were made and cured: $1-\mathrm{WB}=65^{\circ} \mathrm{C}$ during $90 \mathrm{~min}+$ boiling during $90 \mathrm{~min}$ (VC cycle - control group); $2-\mathrm{M} 25=10 \mathrm{~min}$ at $270 \mathrm{~W}+5 \mathrm{~min}$ at $0 \mathrm{~W}+10 \mathrm{~min}$ at $360 \mathrm{~W}$ (VW cycle); 3-M3 = $3 \mathrm{~min}$ at $550 \mathrm{~W}$; and $4-\mathrm{M} 5=5 \mathrm{~min}$ at 650 W. Afterward, they were polished and dried in a dessicator until a constant mass was reached. Specimens were then immersed in distilled water at $37^{\circ} \mathrm{C}$ and weighed regularly until a constant mass was achieved. For porosity, an additional weight was made with the specimen immediately immersed in distilled water. For water sorption and solubility, the specimens were dried again until equilibrium was reached. Data were submitted to 2 way-ANOVA and Tukey HSD ( $\alpha=0.05)$. Results: Porosity mean values below $1.52 \%$ with no significant difference among groups for both materials were observed. Resins showed water sorption and solubility values without a significant difference. However, there was a significant difference among groups for these both properties $(\mathrm{P}<0.013)$. The highest sorption $(2.43 \%)$ and solubility $(0.13 \%)$ values were obtained for WB and M3, respectively. Conclusions: The conventional acrylic resin could be polymerized in a microwave since both the materials showed similar performance in the evaluated properties. Shorter microwave cycles could be used for both the materials without any detectable increase in volume porosity.

Keywords: Polymethyl methacrylate. Polymerization. Porosity. Solubility. Sorption.

1Universidade Estadual de Ponta Grossa, Departamento de Odontologia, Ponta Grossa, Paraná, Brasil.

Universidade de São Paulo, Faculdade de Odontologia de Bauru, Departamento de Prótese e Periodontia, Bauru, São Paulo, Brasil. 


\section{Introduction}

Polymethyl methacrylate acrylic resin has been the material of choice for making denture bases since the beginning of the twentieth century. This material has been modified in order to improve physical and mechanical properties and facilitate the laboratory procedure using microwave polymerization, visible light curing, and vacuum pressure at low temperature curing systems ${ }^{24}$.

During the microwave polymerization, there is a rapid and homogeneous internal heating ${ }^{6}$. This alternative polymerization method has advantages such as ease and cleanliness during acrylic resin processing ${ }^{12}$, rapid temperature increase ${ }^{17}$ and, thus, a reduction in execution time ${ }^{6}$, minimum color change in the denture base acrylic resin and less risk of artificial teeth fracture during deflasking ${ }^{16}$.

The importance of the proper selection of the microwave curing cycle has been reported in order to prevent overheating of the monomer that could cause degradation ${ }^{8}$, porosity and consequent injury to the properties of the prosthesis ${ }^{6}$. According to Bafile, et al. ${ }^{2}$ (1991), resins designed for microwave polymerization could contain triethylene or tetraethylene glycol dimethacrylate in their composition. These dimethacrylates have low vapor pressure, allowing the polymerization to be carried out at elevated temperatures (between $100^{\circ} \mathrm{C}$ and $150^{\circ} \mathrm{C}$ ) without risk of porosity, which would not occur with methyl methacrylate since it has a high vapor pressure.

The porosity is a non-desirable characteristic to the acrylic resin denture base ${ }^{24}$. Severe porosity can weaken the prosthesis and result in high internal stress, leading to greater vulnerability to distortion and warpage $^{29}$. A porous surface promotes colonization of the material by oral microorganisms such as Candida albicans ${ }^{14}$ and facilitates the retention of substances and deposition of calculus, resulting in staining and impaired aesthetic ${ }^{24,30}$. Water absorbed by acrylic resins during the use of prosthesis acts as a plasticizer and can result in volume changes, so the water sorption evaluation also has clinical relevance. Furthermore, residual monomer and other water soluble byproducts are released into the oral cavity and may cause tissue irritation; therefore, it is desired that these materials have low solubility ${ }^{5}$.

Despite the advantages of microwave polymerization, this method has gained only limited clinical acceptance, and materials specifically formulated for use in a microwave have a higher cost compared to those for conventional polymerization. Thus, aiming to overcome these disadvantages, the polymerization of a conventional resin was tested in a microwave oven, and this study evaluated the porosity and water sorption and solubility properties of the acrylic resins Vipi Cril (VC) and Vipi Wave (VW) after polymerization using experimental microwave cycles and the cycles recommended by the manufacturer. The hypotheses evaluated in this study were: 1 ) there would be differences regarding the porosity results between the materials in the evaluated polymerization cycles; and 2) the water sorption and solubility results would be different between the materials conventionally polymerized or cured in a microwave.

\section{Material and Methods}

\section{Material}

The acrylic resins selected for this study are shown in Figure 1.

\section{Specimen preparation}

For the analysis of porosity, specimens $(n=10)$ were made in the dimensions of $50 \times 4 \times 2 \pm 0.1 \mathrm{~mm}^{10}$. Metal matrixes in such dimensions were molded using laboratory silicone (Zetalabor-Zhermack; Labordental,

\begin{tabular}{|c|c|c|c|c|c|}
\hline \multirow{2}{*}{$\begin{array}{c}\text { Material } \\
\text { (acronym) }\end{array}$} & \multirow[t]{2}{*}{ Type } & \multicolumn{2}{|c|}{ Composition* (batch) } & \multirow{2}{*}{$\begin{array}{l}\text { Powderl } \\
\text { liquid ratio }\end{array}$} & \multirow[t]{2}{*}{ Manufacturer } \\
\hline & & Powder & Liquid & & \\
\hline $\begin{array}{l}\text { Vipi Cril@ } \\
\quad(\mathrm{VC})\end{array}$ & Conventional & $\begin{array}{l}\text { PMMA, benzoyl peroxide, } \\
\text { pigments }(0083)\end{array}$ & $\begin{array}{l}\text { MMA, EGDMA, } \\
\text { inhibitor (12087) }\end{array}$ & $2.15 \mathrm{~g} / 1 \mathrm{~mL}$ & $\begin{array}{l}\text { Vipi Ltda., } \\
\text { Pirassunga, SP, Brazil }\end{array}$ \\
\hline $\begin{array}{l}\text { Vipi Wave® } \\
\text { (VW) }\end{array}$ & $\begin{array}{l}\text { Microwaved- } \\
\text { processed }\end{array}$ & $\begin{array}{l}\text { PMMA, benzoyl peroxide, } \\
\text { pigments }(12041)\end{array}$ & $\begin{array}{l}\text { MMA, EGDMA, } \\
\text { inhibitor (12049) }\end{array}$ & $2.15 \mathrm{~g} / 1 \mathrm{~mL}$ & $\begin{array}{l}\text { Vipi Ltda., } \\
\text { Pirassunga, SP, Brazil }\end{array}$ \\
\hline
\end{tabular}

*According to the MSDS provided by the manufacturer.

PMMA: polymethyl methacrylate; MMA: methyl methacrylate; EGDMA: ethylene glycol dimethacrylate

Figure 1- Denture base acrylic resins used in this study 
São Paulo, SP, Brazil) between two glass plates. For the analysis of water sorption and solubility, specimens $(n=10)$ were made in the dimensions of $50 \mathrm{~mm}$ in a diameter $\times 0.5 \mathrm{~mm}$ thickness ${ }^{10}$ using metal matrixes.

The mold/matrix set or just the metal matrix was included in metallic (OGP, Bragança Paulista, SP, Brazil) or plastic (Vipi Ltda., Pirassununga, SP, Brazil) flasks using type III stone (Herodent; Vigodent Coltène SA Ind. e Com., Rio de Janeiro, RJ, Brazil). The flask was closed and remained under a load of $0.5 \mathrm{t}$ in a hydraulic press ( $\mathrm{VH}$, Araraquara, SP, Brazil) during the setting time of the stone. After this period, the materials were handled according to the manufacturer's instructions (Figure 1) and inserted into the mold inside the flask, which was kept under a load of $1.25 \mathrm{t}$ during $30 \mathrm{~min}$. The specimens were then submitted to conventional (SL-155/22; Solab, Piracicaba, SP, Brazil) or microwave (MEF 41; Electrolux, Manaus, AM, Brazil) polymerization cycles as shown in Figure 2.

Then the flasks were bench cooled for $30 \mathrm{~min}$ and subsequently cooled in running water for 15 min before the removal of the specimens. For the porosity analysis, the specimens were polished (Aropol E; Arotec, Cotia, SP, Brazil) using silicon carbide sandpapers (\#100, \#240, and \#600; 3M, Campinas, SP, Brazil) under constant water irrigation. For the water sorption and solubility specimens, a minicutt carbide bur (Edenta; Bergün, Graubünden, Switzerland) was used to remove irregularities of their edges. The specimens were then visually examined, and only those with minimal porosity were used ${ }^{10}$.

\section{Porosity}

Porosity was related to the amount of absorbed water by each specimen after storing in distilled water at $37^{\circ} \mathrm{C}$. The samples were weighed on a digital analytical balance (four decimal places AW220; Shimadzu do Brazil, São Paulo, SP, Brazil) in two stages. In the first one, the specimen was daily weighed after a storing period in a desiccator (Vidrolabor, São Paulo, SP, Brazil). In the second one, the specimen was also daily weighed after a storing period in distilled water in an oven (New Instruments, Piracicaba, SP, Brazil) at $37^{\circ} \mathrm{C}$. The final record of weighing for dry and wet specimens was carried out at the time that they reached a stable mass, evidenced after stabilization in a milligram scale.

The porosity was analyzed using the gravimetric method based on Archimedes' principle ${ }^{2,4,18,21}$ and, therefore, an additional weighing was performed after each stage with the specimen immersed in distilled water.

Thereafter, the porosity was calculated according to the following equations:

Vs dry $=\left(m_{d}-m_{d}{ }^{\prime}\right) / \rho_{\text {water }}$

Vs wet $=\left(m_{w}-m_{w}{ }^{\prime}\right) / \rho_{\text {water }}$

Porosity \% = $100 \times$ (Vs dry - Vs wet)/Vs dry [3]

where: Vs $\operatorname{dry}(\mathrm{mL})$ is the volume of the dry specimen; $m_{d}(g)$ is the mass of the dry specimen recorded in air; $m_{d}{ }^{\prime}(g)$ is the mass of the dry specimen recorded with the specimen immediately immersed in water; $\rho_{\text {water }}(\mathrm{g} / \mathrm{mL})$ is the density of water; Vs wet $(\mathrm{mL})$ is the volume of the wet specimen; $\mathrm{m}_{\mathrm{w}}(\mathrm{g})$ is the mass of the wet specimen recorded in air; and $\mathrm{m}_{\mathrm{w}}{ }^{\prime}$ (g) is the mass of the wet specimen recorded with the specimen immediately immersed in water.

\section{Water sorption and solubility}

Specimens were subjected to a drying process in order to achieve a constant weight. So, they were

\begin{tabular}{|c|c|c|}
\hline Group & Polymerization cycle & Reference \\
\hline $\begin{array}{c}\text { WB } \\
\text { (water-bath - conventional } \\
\text { polymerization) }\end{array}$ & $\begin{array}{l}\text { - immerse the flask in cold water; } \\
\text { - heat water up to } 65^{\circ} \mathrm{C} \text { during } 30 \text { min and maintain } \\
\text { for } 1 \mathrm{~h} \text {; } \\
\text { - heat water until boiling point during } 30 \mathrm{~min} \text { and } \\
\text { maintain for } 1 \mathrm{~h} \text {; } \\
\text { - turn off the water-bath and let cool down }\end{array}$ & $\begin{array}{l}\text { Manufacturer's recommended cycle to } \\
\text { cure VC resin }\end{array}$ \\
\hline $\begin{array}{c}\mathrm{M} 25 \\
\text { (microwave polimerization during } \\
25 \mathrm{~min} \text { ) }\end{array}$ & $\begin{array}{l}270 \mathrm{~W} \text { for } 10 \mathrm{~min} \\
0 \mathrm{~W} \text { for } 5 \mathrm{~min} \\
360 \mathrm{~W} \text { for } 10 \mathrm{~min}\end{array}$ & $\begin{array}{l}\text { Manufacturer's recommended cycle to } \\
\text { cure VW resin }\end{array}$ \\
\hline $\begin{array}{c}\mathrm{M} 3 \\
\text { (microwave polymerization during } \\
3 \mathrm{~min} \text { ) }\end{array}$ & $550 \mathrm{~W}$ for $3 \mathrm{~min}$ & Ilbay, et al. ${ }^{9}$ (1994) \\
\hline $\begin{array}{c}\text { M5 } \\
\text { (microwave polymerization during } \\
5 \mathrm{~min} \text { ) }\end{array}$ & $650 \mathrm{~W}$ for $5 \mathrm{~min}$ & Patil, et al. ${ }^{20}$ (2009) \\
\hline
\end{tabular}

Figure 2- Experimental polymerization cycles evaluated in this study 
kept in a vacuum desiccator and daily weighed on a digital analytical balance until the difference between sequential weight measurements was less than 0.5 mg. After obtaining the constant mass, specimens were stored in distilled water at $37^{\circ} \mathrm{C}$ and were also daily weighed until stabilization, but always after careful drying with absorbent paper.

To calculate the water sorption and solubility, specimens passed again by the above drying process. The water sorption and solubility percentages were calculated using the following equations ${ }^{15}$ :

$$
\begin{aligned}
& \% \text { Sorption }=100 \times\left(m_{2}-m_{3}\right) / m_{1} \\
& \% \text { Solubility }=100 \times\left(m_{1}-m_{3}\right) / m_{1}
\end{aligned}
$$

where: $m_{2}$ is the mass $(\mathrm{mg})$ of the specimen after immersion in water; $m_{3}$ is the mass $(\mathrm{mg})$ of the specimen after the second drying; and $m_{1}$ is the mass (mg) of the specimen after the first drying.

\section{Statistical analysis}

The results of porosity, water sorption and solubility (\%) were analyzed using two-way ANOVA ("material" and "polymerization cycle" factors) and followed by Tukey HSD test $(\alpha=0.05)$ using a personal software (IBM SPSS 19; SPSS Inc., IBM Company, Armonk, NY, USA). Post-hoc power analysis was performed for statistical analyses of all data using the personal statistical software (IBM SPSS 19).

\section{Results}

For the number of specimens used to evaluate the porosity, water sorption and solubility properties $(n=10)$ of denture base acrylic resins, this study showed adequate power for both factors "material"

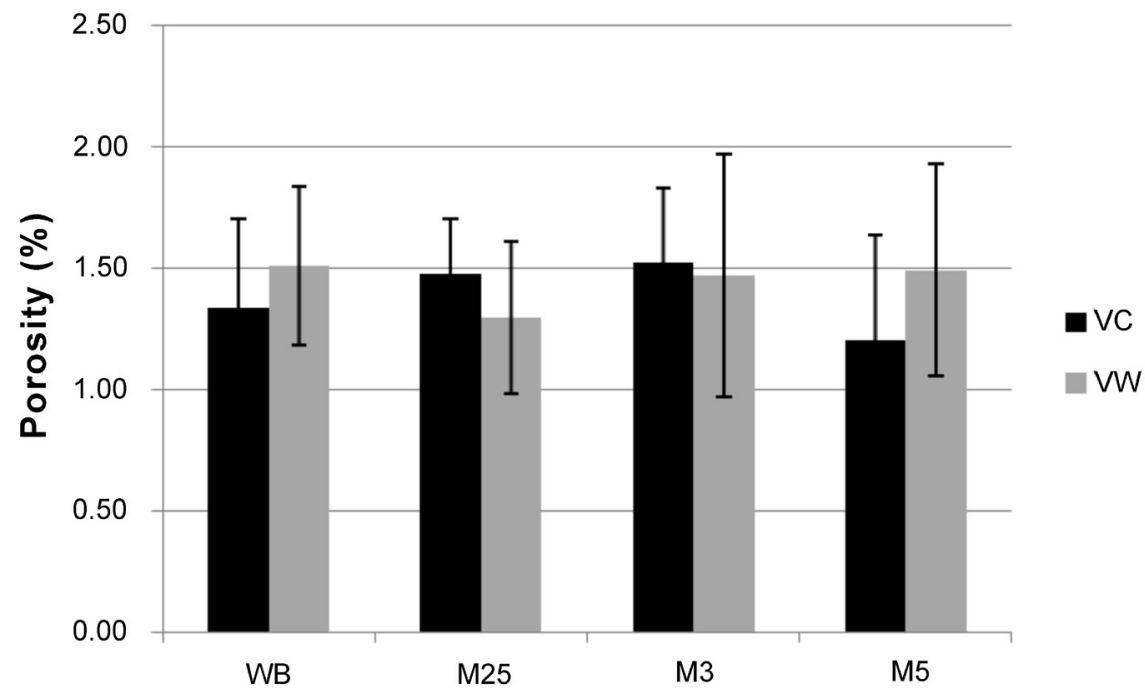

Figure 3- Mean and standard deviation porosity values (\%) for VC and VW resins polymerized in water-bath and microwave cycles

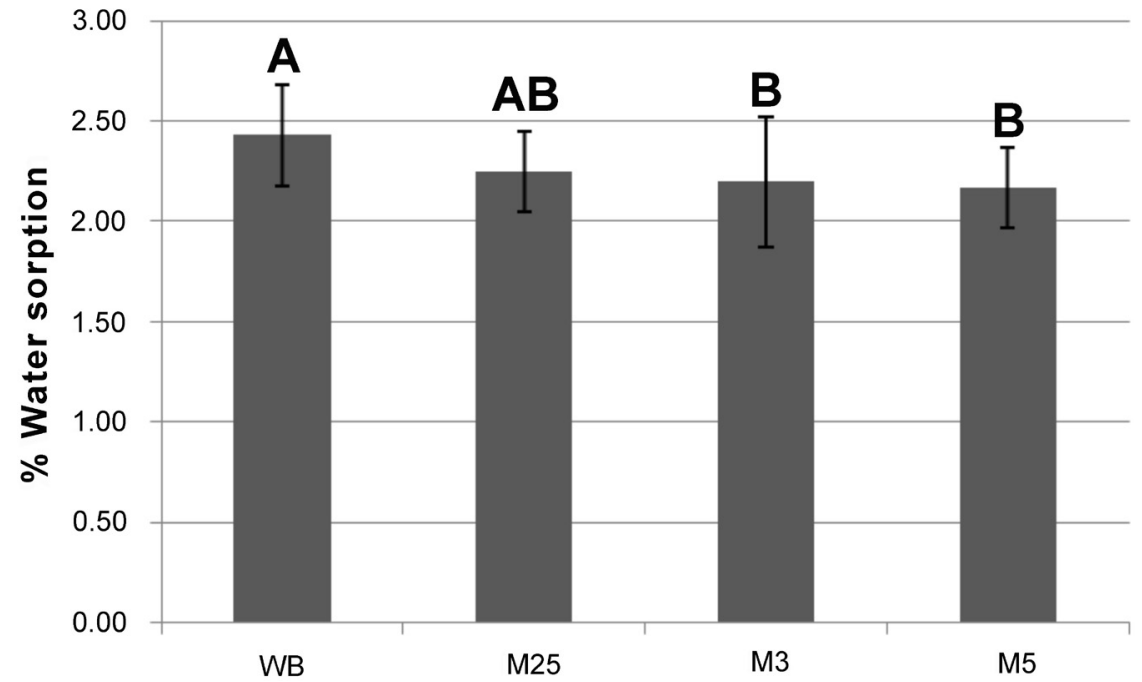

Figure 4- Mean and standard deviation water sorption values (\%) obtained polymerizing in water-bath and microwave cycles regardless of the material. Identical capital letters indicate values with no statistically significant difference $(P>0.05)$ 


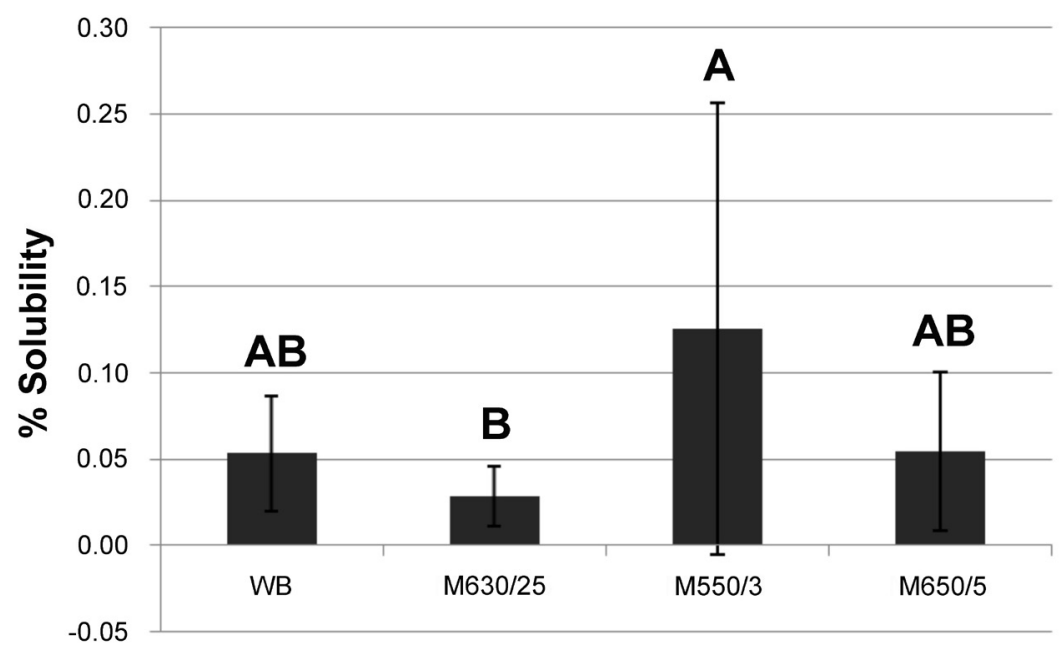

Figure 5- Mean and standard deviation solubility values (\%) obtained polymerizing in water-bath and microwave cycles regardless of the material. Identical capital letters indicate values with no statistically significant difference $(P>0.05)$

and "polymerization cycle" for the three properties $(100 \%, 85.2 \%$, and $80.4 \%$, respectively; $a=0.05)$.

The porosity results are shown in Figure 3. There were no significant differences $(P>0.05)$ between the evaluated polymerization cycles for both the materials, and the observed mean values were less than $1.52 \%$.

For the water sorption and solubility analyses, there was no significant difference between the acrylic resins $(P>0.05)$. However, significant differences were noted $(P<0.013)$ among the experimental cycles for both the properties (Figures 4 and 5). According to Figure 4 , the highest water sorption mean values were obtained in the WB cycle $(2.43 \%)$; intermediate values in the M25 cycle (2.25\%); and the lowest values in the experimental microwave cycles M3 (2.20\%) and M5 (2.17\%). Figure 5 shows that the M3 cycle resulted in the highest mean solubility values $(0.13 \%)$; intermediate values were observed in the M5 and WB cycles $(0.05 \%)$; and the lowest values in the M25 cycle $(0.03 \%)$.

\section{Discussion}

The first hypothesis evaluated in this study, in which "there would be differences regarding the porosity results between the materials in the evaluated polymerization cycles", was not accepted, since no significant differences were observed between the acrylic resins conventionally polymerized in the waterbath or processed in a microwave.

A variety of methods have been used to measure the porosity of acrylic resins using microscopy, mercury porosimetry and the classic method by measuring the weight of the specimen before and after immersion in water, the volume of the specimen and density of acrylic resin and the water and air confined in the pores $^{2,4,30}$. According to Yannikakis, et al. ${ }^{30}$ (2002) the classic method is more objective but does not provide detailed information on the size and location of the pores. However, this study aimed not to describe the pores but objectively compare the polymerized groups according to the manufacturer's instructions or experimentally.

The porosity is a complex phenomenon attributed to a variety of factors depending on the laboratory technique and partially on the conjunction of the polymerization method and material ${ }^{13,30}$. All factors related to the laboratory technique that would influence the porosity results; the proportioning and incorporation of the powder to the liquid; and the pressing, cooling of the flask and polishing time were controlled ${ }^{19}$. The results of other studies ${ }^{2,9,19}$ also found no significant differences in porosity values when the thicknesses of the specimens polymerized in several cycles were around $3 \mathrm{~mm}$. Also, Yannikakis, et al. ${ }^{30}$ (2002) reported that it is possible to polymerize a conventional resin in a microwave when its thickness is equal or less than $3 \mathrm{~mm}$, since this thickness is representative of dimensions commonly used for making denture base ${ }^{30}$. With regard to materials, a similarity in their composition could be noted in Figure 1 that shows the information provided by the manufacturer. Thus, it is possible to suppose that there was no difference between the results of porosity due to standardization in the laboratory technique, the thickness of the specimens and the similar composition of the materials. 
According to the American Dental Association specifications, there should be no bubbles or voids in the denture base polymer when viewed without magnification. Furthermore, porosity values above $11 \%$ have been associated with reduced mechanical properties, impaired appearance and retention of fluids and microorganisms ${ }^{11}$, and levels lower than this one may be considered clinically acceptable ${ }^{24}$. In this study, visible pores and bubbles were not observed and all porosity values were less than $1.52 \%$. Since handling errors were eliminated, the evaporation of the monomer due to the high temperature (external heat + exothermic reaction) is then the most likely cause of the detected internal porosity ${ }^{30}$.

The hypothesis that "the water sorption and solubility results would be different between the materials conventionally polymerized or cured in microwave" was partially proven as there was no difference between the tested materials, but the polymerization cycles resulted in different values for water sorption and solubility.

There are two techniques to quantify the water sorption. The technique recommended by ADA No $12^{1}$ takes into consideration the specimen weight after saturation $\left(m_{2}\right)$ minus the initial dry weight $\left(m_{1}\right)$. This technique assesses the relative sorption of specimens. The technique described by Kazanji and Watkinson ${ }^{15}$ (1988) measures the weight after saturation $\left(m_{2}\right)$ minus the final dry weight $\left(m_{3}\right)$ and not the initial dry weight. This technique is considered the sorption of the polymer network as it takes into account the absorbed liquid minus the liquid released by the material. In the evaluation of water sorption and solubility, the Kazanji and Watkinson technique ${ }^{15}$ (1998) is more representative (data in percent) and has less variable (surface area, results in $\mathrm{mg} / \mathrm{cm}^{2}$ ) in the calculations ${ }^{7}$. In this study, we used the technique recommended by Kazanji and Watkinson ${ }^{15}$ (1998).

The fact that there was no difference between the materials for water sorption and solubility, as well as for porosity, is due to their similar composition as mentioned earlier. The water sorption mean values were between $2.17 \%$ and $2.43 \%$. These values have been considered appropriate since the acrylic resin initially desiccated becomes saturated after sorption of approximately $2 \%$ of water ${ }^{26}$. The solubility values found in this study (between $0.0065 \%$ and $0.4715 \%$ ) were within the range of values observed in another study (between $-0.417 \%$ and $0.815 \%$ ) that evaluated the effect of chemical or mechanical polishing on the solubility of Vipi Cril resin. This large variation, mainly observed in the solubility data, can be attributed to small measured variations in weight? ${ }^{7}$. Lower values of solubility than water sorption are due to slow elution of the residual monomer in comparison to water diffusion ${ }^{26}$. This is because the dissolution of the monomer is 0.5 to $1.7 \times 10^{-2}$ times smaller than the water sorption of the resin based on polymethyl methacrylate 25 .

The acrylic resins contain polar carbonyl groups that therefore attract water molecules ${ }^{26}$. Water molecules, in turn, diffuse between the polymer intermolecular gaps separating them slightly ${ }^{22}$ and gradually infiltrate deeper into the resin ${ }^{26}$. The most important consequence of water sorption is the dimensional change 22 , resulting in change in the vertical dimension of occlusion previously determined. In contrast, it has been reported that the water sorption partially compensates the polymerization shrinkage of heat-polymerized acrylic resin, and after reaching the saturation, the prosthesis should fit better than immediately after processing since there has been no change in paraprosthetic tissues ${ }^{28}$.

The highest water sorption values observed in the water-bath conventional polymerization group may be related to a low residual monomer content ${ }^{5}$ and a higher degree of conversion. The use of a final temperature for at least $30 \mathrm{~min}$ in the water-bath polymerization cycles has led to reduced residual monomer content ${ }^{27}$. This study evaluated the water-bath polymerization recommended by the manufacturer that was included at the end of the cycle a period of $1 \mathrm{~h}$ in boiling for both resins. The reduction of the residual monomer is related to the temperature increase at the end of the polymerization cycle, which results in increased mobility of the molecular chains, thus facilitating the conversion of monomer to polymer ${ }^{23}$. Similarly, the lowest water sorption results observed in $\mathrm{M} 3$ and M5 groups can be associated with a low degree of conversion values. Moreover, the highest solubility values found in the M3 group can be due to a higher residual monomer content ${ }^{20}$ because it has been related to higher levels of solubility of acrylic resins ${ }^{3,5}$.

This study evaluated only two brands of heatpolymerized denture base acrylic resins. Additional studies evaluating physical, mechanical and biological properties and the material behavior after aging conditions are needed to decide if faster microwave 
polymerization cycles can be used to cure conventional acrylic resins.

\section{Conclusions}

Within the limitations of this in vitro study, it can be concluded that the conventional acrylic resin Vipi Cril could be polymerized in a microwave, since both the materials behaved similarly in the evaluated properties. Shorter microwave polymerization cycles could be used for both the materials without any detectable increase in volume porosity. The lowest water sorption and the highest solubility values were detected by using the microwave polymerization at $550 \mathrm{~W}$ for $3 \mathrm{~min}$.

\section{Acknowledgements}

This study was supported by Fundação Araucária (FA 2009/17471-PPP).

\section{References}

1- American Dental Association. Revised American Dental Association specification no. 12 for denture base polymers. J Am Dent Assoc. 1975;90:451-8.

2- Bafile M, Graser GN, Myers ML, Li EK. Porosity of denture resin cured by microwave energy. J Prosthet Dent. 1991;66:269-74.

3- Bates JF, Stafford GD, Huggett R, Handley RW. Current status of pour type denture base resins. J Dent. 1977;5:177-89.

4- Compagnoni MA, Barbosa DB, de Souza RF, Pero AC. The effect of polymerization cycles on porosity of microwave-processed denture base resin. J Prosthet Dent. 2004;91:281-5.

5- Cucci AL, Vergani CE, Giampaolo ET, Afonso MC. Water sorption, solubility, and bond strength of two autopolymerizing acrylic resins and one heat-polymerizing acrylic resin. J Prosthet Dent. 1998;80:434-8. 6- De Clerck JP. Microwave polymerization of acrylic resins used in dental prostheses. J Prosthet Dent. 1987;57:650-8.

7- El-Hadary A, Drummond JL. Comparative study of water sorption, solubility, and tensile bond strength of two soft lining materials. J Prosthet Dent. 2000;83:356-61.

8- Gettleman L, Nathanson D, Myerson RL. Effect of rapid curing procedures on polymer implant materials. J Prosthet Dent. 1977;37:7482

9- Ilbay SG, Guvener S, Alkumru HN. Processing dentures using a microwave technique. J Oral Rehabil. 1994;21:103-9.

10- International Organization for Standardization. Specification 1567: denture base polymers. Switzerland: ISO; 2001.

11- Jerolimov V, Brooks SC, Huggett R, Bates JF. Rapid curing of acrylic denture-base materials. Dent Mater. 1989;5:18-22.

12- Kartika UK, Agrawal B, Yadav NS, Singh PP, Rahangdale T. The effect of microwave processing and use of antimicrobial agent on porosity of conventional heat cured denture base resin: an in vitro study. J Indian Prosthodont Soc. 2015;15:257-62.
13- Kasina SP, Ajaz T, Attili S, Surapaneni H, Cherukuri M, Srinath HP. To evaluate and compare the porosities in the acrylic mandibular denture bases processed by two different polymerization techniques, using two different brands of commercially available denture base resins - an in vitro study. J Int Oral Health. 2014;6:72-7.

14- Kattadiyil MT, Jekki R, Goodacre CJ, Baba NZ. Comparison of treatment outcomes in digital and conventional complete removable dental prosthesis fabrications in a predoctoral setting. J Prosthet Dent. 2015;114:818-25.

15- Kazanji MN, Watkinson AC. Soft lining materials: their absorption of, and solubility in, artificial saliva. Br Dent J. 1988;165:91-4.

16- Kimura H, Teraoka F, Ohnishi H, Saito T, Yato M. Applications of microwave for dental technique (part 1). Dough-forming and curing of acrylic resins. J Osaka Univ Dent Sch. 1983;23:43-9.

17- Lai YL, Chen YT, Lee SY, Shieh TM, Hung SL. Cytotoxic effects of dental resin liquids on primary gingival fibroblasts and periodontal ligament cells in vitro. J Oral Rehabil. 2004;31:1165-72.

18- Lima JF, Maciel JG, Hotta J, Vizoto AC, Honorio HM, Urban VM, et al. Porosity of temporary denture soft liners containing antifungal agents. J Appl Oral Sci. 2016;24:453-61.

19- Oliveira VM, Leon BL, Del Bel Cury AA, Consani S. Influence of number and position of flasks in the monomer release, Knoop hardness and porosity of a microwave-cured acrylic resin. J Oral Rehabil. 2003;30:1104-8.

20- Patil PS, Chowdhary R, Mandokar RB. Effect of microwave postpolymerization treatment on residual monomer content and the flexural strength of autopolymerizing reline resin. Indian J Dent Res. 2009;20:293-7

21- Pero AC, Barbosa DB, Marra J, Ruvolo-Filho AC, Compagnoni MA. Influence of microwave polymerization method and thickness on porosity of acrylic resin. J Prosthodont. 2008;17:125-9.

22- Ristic B, Carr L. Water sorption by denture acrylic resin and consequent changes in vertical dimension. J Prosthet Dent. 1987;58:689-93.

23- Sideridou I, Achilias DS, Kyrikou E. Thermal expansion characteristics of light-cured dental resins and resin composites. Biomaterials. 2004;25:3087-97.

24- Singh S, Palaskar JN, Mittal S. Comparative evaluation of surface porosities in conventional heat polymerized acrylic resin cured by water bath and microwave energy with microwavable acrylic resin cured by microwave energy. Contemp Clin Dent. 2013;4:147-51.

25- Takahashi Y, Chai J, Kawaguchi M. Equilibrium strengths of denture polymers subjected to long-term water immersion. Int J Prosthodont. 1999; 12:348-52.

26- Tsuboi A, Ozawa K, Watanabe M. Water absorption characteristics of two types of acrylic resin obturators. J Prosthet Dent. 2005;94:382-8. 27- Urban VM, Machado AL, Oliveira RV, Vergani CE, Pavarina AC, Cass QB. Residual monomer of reline acrylic resins. Effect of waterbath and microwave post-polymerization treatments. Dent Mater. 2007;23:363-8.

28- Woelfel JB, Paffenbarger GC, Sweeney WT. Dimensional changes occurring in dentures during processing. J Am Dent Assoc. 1960;61:413-30.

29- Wolfaardt JF, Cleaton-Jones P, Fatti P. The occurrence of porosity in a heat-cured poly (methyl methacrylate) denture base resin. J Prosthet Dent. 1986;55:393-400.

30- Yannikakis S, Zissis A, Polyzois G, Andreopoulos A. Evaluation of porosity in microwave-processed acrylic resin using a photographic method. J Prosthet Dent. 2002;87:613-9. 